\section{Células madre como tratamiento regenerativo para la enfermedad de Parkinson}

\section{Stem cells as a regenerative treatment for Parkinson's disease \\ Células-tronco como tratamento regenerativo da doença de Parkinson}

\author{
Yoetsy García \\ yoetsygar@gmail.com \\ Roxana González \\ roxanalejandra.1@gmail.com \\ Francisco Rangel \\ fran_emanuel@hotmail.com \\ Víctor Torres \\ victortm07@gmail.com
}

Recibido enero 2019 / Revisión febrero 2019 / Aceptado 1 de mayo 2019

\section{RESUMEN}

Introducción: El Parkinson es una enfermedad neurodegenerativa, poco frecuente dentro de una población, ésta presenta una sintomatología que afecta el movimiento de pacientes que la padecen. La medicina regenerativa en los últimos años da lugar a la posibilidad de curar enfermedades degenerativas, incluyendo la enfermedad de Parkinson, utilizando la capacidad terapéutica de las células madre. Objetivo: Indagar en diferentes artículos científicos, un tratamiento para la enfermedad de Parkinson a partir de las células madre y su implementación en pacientes que sufran esta enfermedad. Materiales y métodos: Se realizó una revisión bibliográfica incluyendo los descriptores relacionados a células madres y enfermedad de Parkinson. Resultados: Las terapias celulares a partir de las células madre a pesar de ser pocas, se han intentado implementar como tratamiento en la medicina regenerativa, es por esto que mediantes los nuevos avances en la medicina regenerativa se tiene la esperanza que los tratamientos o terapias celulares para la EP se puedan implementar en pacientes que se encuentren en etapas avanzadas de dicha enfermedad, con el fin de revertir los síntomas o en mejores instancias regenerar las células dopaminérgicas de la sustancia negra.

Palabras clave: Células madre; enfermedad de Parkinson; tratamiento

\begin{abstract}
Introduction: Parkinson's is a neurodegenerative disease, rare in a population, it presents a symptomatology that affects the movement of patients who suffer from it. Regenerative medicine in recent years gives rise to the possibility of curing degenerative diseases, including Parkinson's disease, using the therapeutic capacity of stem cells. Objective: To investigate in different scientific articles, a treatment for Parkinson's disease from stem cells and its implementation in patients suffering from this disease. Materials and methods: A bibliographic review was carried out including the descriptors related to stem cells and Parkinson's disease. Results: Cellular therapies from stem cells, despite being few, have been tried to be implemented as a treatment in regenerative medicine, that is why, by means of new advances in regenerative medicine, it is hoped that cell treatments or therapies for PD can be implemented in patients who are in advanced stages of this disease, in order to reverse the symptoms or in better instances to regenerate the dopaminergic cells of the substantia nigra.
\end{abstract}

Key words: Stem cells; Parkinson's disease; treatment
YG: Universidad de Carabobo, Venezuela.

RG: Universidad de Carabobo, Venezuela.

FR: Universidad de Carabobo, Venezuela.

VT: Universidad de Carabobo, Venezuela. 


\section{RESUMO}

YG: Universidad de Carabobo, Venezuela.

RG: Universidad de Carabobo, Venezuela.

FR: Universidad de Carabobo, Venezuela.

VT: Universidad de Carabobo, Venezuela.
Introdução: O Parkinson é uma doença neurodegenerativa, rara em uma população, apresenta uma sintomatologia que afeta o movimento de pacientes que sofrem com ela. A medicina regenerativa nos últimos anos dá origem à possibilidade de curar doenças degenerativas, incluindo a doença de Parkinson, usando a capacidade terapêutica das células-tronco. Objetivo: Investigar em diferentes artigos científicos, um tratamento para a doença de Parkinson a partir de células-tronco e sua implementação em pacientes que sofrem dessa doença. Materiais e métodos: Foi realizada uma revisão bibliográfica, incluindo os descritores relacionados às células-tronco e à doença de Parkinson. Resultados: As terapias celulares de células-tronco, apesar de poucas, têm tentado ser implementadas como tratamento na medicina regenerativa, por isso, por meio de novos avanços na medicina regenerativa, espera-se que tratamentos ou terapias celulares para a DP, eles podem ser implementados em pacientes que estão em estágios avançados da referida doença, a fim de reverter os sintomas ou, em melhores casos, regenerar as células dopaminérgicas da substância negra.

Palavras-chave: Células-tronco; Doença de Parkinson; tratamento

\section{INTRODUCCIÓN}

$\mathrm{L}$ a enfermedad de Parkinson (EP) es una enfermedad degenerativa la cual se caracteriza principalmente por un temblor que se desarrolla en un estado de reposo, además de rigidez, bradicinesia y pérdida de los reflejos posturales. Hasta la actualidad no se conoce con exactitud una causa que desarrolle esta enfermedad pero al pasar el tiempo investigadores han establecidos que la EP es provocada por la degeneración de células que sintetizan el neurotransmisor dopamina, sumándole también una disminución de conexiones con otras células nerviosas y músculos, lo cual puede presentarse de forma repentina en una persona, esta será conducida con el tiempo a un estado de incapacidad provocada por la destrucción de neuronas denominadas cómo sustancia negra, por causa que aún en la actualidad y a pesar de todos los avances tecnológicos desarrollados por la ciencia se desconocen $(1,2)$.

Hoy en día la enfermedad de Parkinson se considera la segunda enfermedad neurodegenerativa más común en las personas a nivel mundial, además está extendida por todo el mundo y afecta tanto al sexo masculino cómo al femenino, siendo frecuente que aparezca a partir del sexto decenio de vida, sin embargo, a pesar de esta variedad tardía, existe una versión precoz que se manifiesta en edades inferiores de cuarenta años.

Para esta enfermedad neurodegenerativa solo existen tratamientos que tienen como objetivo principal tratar los síntomas para hacer más llevadera la EP. Una de las razones más notoria que hace difícil el desarrollo de una cura para la enfermedad de Parkinson, es que la ubicación del tejido dañado se encuentra profundamente en el cerebro, siendo esto un área sensible vuelve complicado la administración de tratamientos, que erradiquen por completo la degeneración neurológica. Sin embargo, aunque no existe una cura oficial se puede administrar a los pacientes con enfermedad de Parkinson medicamentos que neutralicen los síntomas de esta enfermedad de manera temporal, o mientras se esté bajo el efecto de los fármacos (2).

Después de diversos estudios en medicina regenerativa, se ha demostrado la capacidad que tienen las células madre 
para renovar tejido dañado, por esta razón, cada vez parece más viable cómo solución a enfermedades degenerativas. La implementación de las células madre en el organismo de los pacientes con enfermedades degenerativas podrían ser favorables para la regeneración del desgaste en tejidos afectados a causa de la enfermedad de Parkinson, ya que estas células madre se activan y tienen la tarea de reparar los tejidos dañados o sustituir si es necesario las células atrofiados o que han muerto.

A partir de estos planteamientos se propone como objetivo general indagar sobre tratamientos que puedan ser utilizados para la regeneración de los tejidos cerebrales, atrofiados en pacientes con la enfermedad de Parkinson mediante la implementación de células madre.

\section{MATERIALES Y MÉTODO}

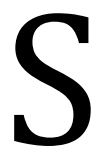
e realizó una investigación descriptiva y documental, con revisión de la literatura bien físico en libros y artículos, también fuentes virtuales, en un metabuscador (golpe) y bases digitales, Biblioteca Virtual de Salud (BVS) y SciELO, Google Scholar y repositorios institucionales. Se revisaron artículos en inglés, y español según descriptores: Células madre, enfermedad de Parkinson, tratamiento regenerativo.

\section{RESULTADOS Y DISCUSIÓN}

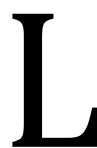
os avances recientes obtenidos en genética molecular han revelado influencias genéticas importantes en la EP. En 1977, con el hallazgo de mutaciones en el gen codificante de la alsinucleina en formas autonómicas dominantes de la EP y la alfasinucleina fue la primera proteína implicada en la EP. Estos últimos están presentes no sólo en los pacientes portadores de la mutación del gen, sino también en aquellos con la forma esporádica de la EP, de allí que los avances genéticos lleven a un entendimiento mayor de la patogénesis de la EP. Hasta el presente se han identificado por lo menos once formas genéticamente diferentes de la enfermedad de Parkinson (3).

Se ha demostrado que en la EP existe perdida neuronal y de pigmentación de la sustancia negra y en otros núcleos subcorticales pigmentados. La gravedad de los cambios de la sustancia negra es paralela a la reducción y perdida de dopamina en el cuerpo estriado, esto debido a que la zona compacta de la sustancia negra contiene la mayor parte de los cuerpos dopaminérgicos del cerebro $(4,5)$. La denervación del estriado afecta su salida a la corteza a través de los sistemas estriado-pálido-tálamo-cortical (corteza motora) y el sistema negro (parte reticular) (4,6). El circuito motor se encarga en su totalidad del control de los parámetros de movimiento e incluye el área sensorio motora agranular y áreas corticales.

Los síntomas en la EP como el temblor y la rigidez se deben a la disminución de actividad dopaminérgica en el circuito motor. Por esta razón, se ha especulado que la perdida de fibras pálido-corticales es importante en la génesis del temblor y que la rigidez se relaciona con la perdida de fibras estriado-palidales; todo esto está basado en autopsias realizadas en pacientes con EP $(4,7)$. En cuanto a la fisiopatología de los trastornos cognitivos en la EP aún es controvertida. Sin embargo, diversos factores sugieren que la deficiencia de dopamina contribuye al deterioro intelectual. En la EP la reducción máxima de dopamina ocurre en la cabeza antedorsal, que es el área que recibe proyecciones masivas de la corteza prefrontal y particularmente de la convexidad lateral $(4,8)$.

A pesar de que la patología primaria de la EP es la degeneración de la 
proyección dopaminergica al estriado, no todos los síntomas de estos pacientes se atribuyen a la perdida de dopamina. La causa de la EP es desconocida y los principales factores son de naturaleza genética y ambiental. Su diagnóstico es exclusivamente clínico ya que no hay marcadores bioquímicos ni de neuroimagen que lo confirmen y a pesar de las numerosas investigaciones, todavía no se cuenta con un tratamiento que prevenga de forma fiable la presentación de la enfermedad o que detenga su progresión cuando se manifiesta clínicamente o revierta el proceso degenerativo.

En los últimos años se han realizado múltiples estudios con el fin de identificar factores exógenos que pudieran modificar el riesgo de desarrollar la enfermedad de Parkinson. Mediante estudios retrospectivos de casos y controles se ha intentado relacionar el consumo regular de antiinflamatorios no esteroides y ciertas vitaminas con un menor riesgo de contraer la enfermedad pero los resultados obtenidos son contradictorios y no es posible inferir que el consumo de esos fármacos reduzca el riesgo. La asociación más firme en este momento es la mayor incidencia de enfermedad de Parkinson entre no fumadores; existe una relación entre la alteración de los niveles de dopamina producida por el tabaco y una disminución del riesgo de contraer Parkinson, pero los mecanismos de esa relación aún no han sido determinados (9).

\section{Tipos de células madres asociadas a tratamientos regenerativos para la enfermedad de Parkinson}

La historia y el estudio de las células en general han producido un cambio radical en el horizonte de la medicina, permitiendo diseñar nuevos tratamientos que antes se consideraban imposibles para la cura y regeneración de algunas enfermedades. Uno de ellos, es el tratamiento para la enfermedad de
Parkinson, que se produce por la muerte de una célula cerebral.

Las células madre poseen distintas funciones o potenciales, es por esta razón que tanto el investigador como el médico, tienen la esperanza de que ellas formen parte y tengan las suficientes capacidades para llevar a cabo tratamientos que propicien excelentes resultados en la regeneración de la enfermedad de Parkinson (10,11). Existen dos tipos reconocidos de células madre; La diferencia entre ellas radica en la capacidad que posee cada una para generar la línea germinal del organismo.

El requerimiento que tienen las células madre en la enfermedad de Parkinson es regenerar células las cuales sean capaces de sintetizar y liberar dopamina, después de ser implantadas en la zona estriada (12).

Las células madre forman parte de una reserva natural del cuerpo y llevan a cabo funciones para ayudar a mantener las otras células existentes en el organismo, que se encuentran agotadas por sus funciones diarias o que estén dañadas por distintos factores. Estas células se pueden encontrar en el organismo desde la octava semana de gestación o incluso mucho antes, las cuales ya son adultas y son capaces de diferenciarse en cualquier otra célula $(13,14)$.

Según su potencialidad estas células se pueden clasificar en totipotenciales que son aquellas que pueden generar en condiciones apropiadas un individuo completo, pluriponteciales que tienen la habilidad de diferenciarse en tejidos procedentes de cualquiera de las tres capas embrionarias, y por último las multipotenciales, que pueden diferenciarse en distintos tipos celulares pero procedentes de las misma capas embrionarias, lo que las capacita para originar distintos tipos de células pero no todas. 
Según el estado evolutivo de estas células se clasifican en embrionarias y adultas o somáticas (entre las principales células madre potencialmente terapéuticas se han señalado las embrionarias, las fetales, las amnióticas, las de la sangre del cordón umbilical, las adultas y más recientemente, las células con características embrionarias que se han obtenido mediante la reprogramación de células adultas llamadas "células madre pluripotentes inducidas" (15).

Las células madre embrionarias derivan del embrión, exactamente en la etapa donde se le conoce como blastocito y posee la capacidad de generar cualquier célula diferenciada en el organismo. Entre las desventajas de este tipo de célula madre están los problemas éticos que provienen de la necesidad de extraerla de su medio natural, que es un embrión en desarrollo, lo cual equivaldría a la interrupción de la vida de un nuevo ser en proceso de formación, estas células se encuentran en la capa interna del blastocito llamada embrioblasto (16).

En cuanto a las células madre adultas o somáticas, se han definido como células que están restringidas en su capacidad de diferenciarse y que es capaz únicamente de generar células del tejido que representa, sin embargo, en los últimos años se han realizado varios estudios que han aportado resultados sorprendentes, donde sugieren que la potencialidad de algunos tipos de células madre adultas es mayor de lo que se creía, pues han demostrado la capacidad de diferenciarse en células de distintos linajes.

Entre estas células madre adultas presentes en la médula ósea se pueden encontrar no solo las hematopoyéticas como antes se creía, sino también las mesenquimales (estromales) entre otras, pero estas se consideran las más importantes y más utilizadas en ensayos clínicos, terapias celulares, y tratamientos regenerativos.

Estas

células mesenquimáticas 0 mesenquimatosas provenientes del estroma de la médula ósea, son necesarias para el mantenimiento y expansión de células madre hematopoyéticas derivadas de la médula ósea de adultos y de la sangre del cordón umbilical, además pueden diferenciarse en osteoblastos, condroblastos, adipoblastos y mioblastos.

Por otra parte, investigaciones recientes señalan la diferenciación de células con marcadores asociados a las neuronas, lo que proporciona las posibilidades para la aplicación de tratamientos regenerativos en distintas enfermedades con afecciones neurológicas $(17,18)$

Las ventajas de las células madre adultas o somáticas, son que no producen trastornos inmunológicos ni problemas éticos, pueden ser de diferentes tipos y obtenerse de distintas fuentes, pueden auto renovarse y modificar posiblemente su diferenciación y transferencia génica; a pesar de esto estas células tienen su autorenovación limitada y su manipulación es engorrosa y costosa16, sin embargo lo resultados y métodos de obtención de las células madres adultas que provienen de la médula ósea es más flexible y menos costoso (19).

Las células madre, sean las embrionarias $\mathrm{o}$ adultas, son células no especializadas que tienen como función diferenciarse en otro tipo de células especializadas en el organismo, forman una especie de sistema de reparación para el cuerpo dividiéndose potencialmente sin límites para reponer otras células que han sido dañadas. Otra capacidad que tienen es que pueden seguir siendo una célula madre, esto se entiende como autorenovación $(19,20)$.

En muchos tejidos del cuerpo tales como medula ósea, tejido adiposo, tejido sanguíneo y otros órganos como el 
corazón, pueden encontrarse las células madre; mientras que en un embrión se encuentra específicamente en el cordón umbilical o en la capa interna del embrión cuando es blastocito. La auto-renovación es de gran importancia, es la cualidad que las define, pues este proceso se mantiene a lo largo de toda la vida del organismo.

El número y el tipo de células que las células madre producen varía dependiendo del tipo de tejido y del estado de desarrollo, pues a medida que el organismo se desarrolla, el potencial de las células madre para producir cualquier otro tipo de célula del cuerpo se va reduciendo gradualmente.

La mayoría de los ensayos clínicos utilizan las células madre de la mesénquima que derivan de fuentes como el tejido adiposo, la médula ósea y el tejido conectivo, y solo una pequeña parte utilizan las células madre sanguíneas (15).

Entre los ensayos clínicos más avanzados se encuentran aquellos que están dirigidos a tratar ciertas enfermedades o lesiones óseas, cutáneas y corneales mediante un injerto de tejido, que crece a partir de células madre procedentes de estos órganos. A partir de aquí se tiene que las células madre son fundamentales para el mantenimiento de los tejidos de todo el cuerpo, así como la renovación constante de las células de órganos según sus necesidades (15).

\section{Tratamiento regenerativo a partir de las células madre para la enfermedad de Parkinson}

La enfermedad de Parkinson es un proceso degenerativo cerebral de etiología desconocida, que carece de un marcador biológico que permita su diagnóstico definitivo (21). Debido a que la causa de los síntomas es la falta de dopamina, el tratamiento se ha enfocado en la administración de dopamina a través de diferentes medicamentos que hace mejorar los síntomas (22), pero a medida que pasa el tiempo se torna menos eficaz, es así, que, con la esperanza de encontrar un mejor tratamiento, investigadores desde el año de 1980 han estado tratando de reemplazar la deficiencia de la dopamina a través de la traducción de trasplantes de células madre embrionarias.

Las células derivadas de la región media cerebral del feto pueden modificar el curso de esta enfermedad, aunque debe tenerse en cuenta que ellas son una fuente inadecuada de neuronas productoras de dopamina debido a su estabilidad; así, el uso de células madre adultas al diferenciarse son una mejor opción debido a la mayor estabilidad en neuronas degeneradas (15)

En la actualidad se ha ido implementando el término de regeneración dentro de la rama de la medicina, refiriéndose a ella como el proceso mediante el cual un tejido especializado que se ha perdido es reemplazado por la proliferación de células especializadas que no están dañadas (23). Partiendo de este término y las investigaciones que se han realizado de tratamientos especializados para la regeneración de un órgano adulto a través de las células madre, se emplea el concepto de medicina regenerativa $o$ también conocida como ingeniera de los tejidos la cual es una rama de la medicina que se ha desarrollado considerablemente en los últimos años, aplicando estrategias que contribuyen a mejorar los procesos por los que los órganos y los tejidos son capaces de renovarse y restituir su integridad después de sufrir algún daño o enfermedad $(23,24)$.

A lo largo del tiempo los avances científicos sobre la regeneración de un tejido a través de células madre derivadas de la medula ósea ha sido el tema central y más debatido en la aplicación clínica obteniendo resultados positivos en varias 
enfermedades, aunque no se conoce bien los mecanismos mediante los cuales las células trasplantadas podrían mejorar o promover la regeneración de los tejidos. Se han ido estableciendo una serie de hipótesis para poder explicar este fenómeno que incluyen, la transdiferenciación celular, la fusión de células o un efecto autocrino/paracrino secundario a la liberación por las células de diferentes moléculas solubles o citocinas con acciones específicas, que incluyen varios factores de crecimiento.

Probablemente una de estas hipótesis ejecute el mecanismo de acción de este fenómeno regenerativo, se estima que estos mecanismos son realizados por señales que envían las células residentes o contactos que se producen entre ellas y las células trasplantadas, lo que permite su integración apropiada para su acción regenerativa. Igualmente se plantea la fusión de las células implantadas con las células residentes del tejido provocando así la creación de nuevas células características funcionales que dan paso a la participación de la actividad regenerativa (25).

Mediante los nuevos avances dentro del área de la medicina regenerativa, se pueden desarrollar nuevos tratamientos para la enfermedad de Parkinson mediante la aplicación de la terapia celular. Esto se debe a la identificación de varios cocteles de factores de transcripción que permiten la transdiferenciación de fibroblastos humanos adultos en un sub tipo específico de neuronas dopaminérgicas que permiten sustituir las neuronas que degeneran en pacientes con EP.

La medicina regenerativa con células madre naturales 0 inducidas por reprogramación celular ofrece una clara promesa para el tratamiento de estas devastadoras patologías, aunque su proceso de desarrollo se encuentra todavía en un estadio muy temprano. Por su parte, la terapia con células madre adulta se ha evaluado en modelos animales y también en algunos ensayos clínicos para enfermedades neurodegenerativas, como es la enfermedad de Parkinson.

El uso de células madre embrionarias como fuente de neuronas dopaminérgicas para el tratamiento de la enfermedad de Parkinson es un prospecto de creciente interés, y existe evidencia de que las neuronas dopaminérgicas derivadas de células madre embrionarias de ratón sobreviven durante extensos períodos de tiempo (más de 37 semanas).

Las neuronas dopaminérgicas así generadas causan una reversión conductual gradual y sostenida de la asimetría motora mediada por las neuronas dopaminérgicas $(26,27)$. El potencial terapéutico de las células madre mesenquimales se ha examinado también en modelos animales de enfermedad de Parkinson, y se ha evaluado la capacidad neuro-restaurativa intrínseca de las células madre mesenquimales y su utilidad como fuente de neuronas dopaminérgicas.

Al igual que las células madre embrionarias, las células madre pluripotentes inducidas pueden diferenciarse en neuronas dopaminérgicas en cultivo e implantarse subsecuentemente en el cerebro de ratas utilizadas como modelo de enfermedad de Parkinson, donde son capaces de mejorar el comportamiento de los animales (15). La posibilidad de inducir células madre neurales originadas a partir de células somáticas humanas, por ejemplo, fibroblastos, ha abierto nuevos horizontes para la investigación tanto para el tratamiento de enfermedades como para aplicaciones de terapia celular en el campo neurológico.

El hecho de que las células madre neurales inducidas puedan ser expandidas in vitro por un número de pasajes potencialmente ilimitados constituye una 
característica conveniente, ya que las aplicaciones clínicas que involucran trasplante de células madre usualmente requieren grandes cantidades de células del donante (26). Entre los antecedentes de la aplicación clínica de la medicina regenerativa en enfermedades neurodegenerativas, está el uso de injertos de células fetales en pacientes con enfermedad de Parkinson.

A pesar de que los estudios iniciales parecieron prometedores, surgieron varios problemas prácticos que frenaron esta conducta terapéutica, entre ellos los diferentes métodos usados que hacían difícil una adecuada comparación de los resultados, la dificultad para la obtención de células que se necesitan para aplicar como tratamiento, la conservación del material hístico que se utilizaría en el implante y los problemas éticos relacionados con la obtención, manipulación y empleo de tejido fetal humano. Por medio de todos estos estudios y avances tecnológicos e investigaciones realizadas a lo largo de los años la medicina regenerativa abre caminos para la implementación de nuevos tratamientos para aquellas enfermedades neurodegenerativas que no son curables como lo es la enfermedad de Parkinson.

Existen diferentes hipótesis, la muerte neural de las células dopaminérgicas de la sustancia negra y actualmente se habla de enfermedad multifactorial genética, hereditaria y ambiental. Se han descrito 11 mutaciones, asociadas a la Enfermedad de Párkinson. Hasta el momento las células madre, son las mejores candidatas para el tratamiento de las enfermedades neurodegenerativas, ya que son consideradas células neurales, por que logran identifican, localizan y transforman las células, que estén atrofiadas.

Las células madre, sean las embrionarias o adultas, son células no especializadas, que se diferencian en especializadas en el organismo, formando un sistema de reparación en el cuerpo y capaces de seguir siendo una célula madre, lo que se entiende como auto-renovación.

\section{CONCLUSIÓN}

$\mathrm{L}$ a enfermedad de Parkinson es una enfermedad degenerativa a la que no se le conoce una cura, hay necesidad de implementar nuevos tratamientos que ayuden a regenerar los tejidos lesionados o revertir los síntomas causados por la lesión. Las células madre se han vuelto las mejores candidatas debido a sus capacidades para cumplir con las expectativas para estos tratamientos regenerativos. Las células madre se han utilizado para diseñar nuevos tratamientos que permitan la regeneración de tejidos dañados, lo que facilita la cura o hace más llevaderos los síntomas que presentan. Estos tratamientos se encuentran en investigación para poder mejorar las técnicas, y garantizar resultados eficientes que cumplan con las expectativas de los clínicos y pacientes.

En muchos tejidos del cuerpo tales como la medula ósea, el tejido sanguíneo, y otros órganos, pueden encontrarse las células madre y en un embrión se encuentran específicamente en el cordón umbilical o en la capa interna del embrión cuando es blastocito (embrioblasto).

Estas células madre han sido utilizadas en pacientes con alguna lesión, con el fin de restaurar tejido dañado; pero las terapias celulares a partir de las células madre a pesar de ser pocas, se han intentado implementar como tratamiento en la medicina regenerativa, es por esto que mediantes los nuevos avances en la medicina regenerativa se tiene la esperanza que los tratamientos o terapias celulares para la EP se puedan implementar en pacientes que se encuentren en etapas avanzadas de dicha enfermedad, con el fin de revertir los 
síntomas o en mejores instancias regenerar las células dopaminérgicas de la sustancia negra.

- Los autores declaran no poseer conflictos de interés.

- Estudio realizado bajo los estatutos bioéticos.

- Ente financiador: La investigación no conto con financiamiento alguno.

\section{REFERENCIAS BIBLIOGRÁFICAS}

1. Micheli F. Enfermedad de Parkinson y trastornos relacionados [En línea].2 ed. Buenos aires: medica panamericana; 2016 [Fecha de acceso 8 de junio del 2016]. Disponible en: http://www.medicapanamericana.com

2. Rodríguez J, Díaz Y, Rojas Y. Actualización en enfermedad de Parkinson idiopática. CCM [Internet]. 2013 [citado 2018 Feb 25]; $17(2):$ 163-177. Disponible en: http://scielo.sld.cu/scielo.php?script= sci_arttext\&pid=S156043812013000200007\&lng=es

3. Marín D, Carmona H, Ibarra M, Gámez M. Enfermedad de Parkinson: fisiopatología, diagnóstico y tratamiento. Rev. Univ. Ind. Santander. Salud [Internet]. 2018 [citado 2018 dic 20]; 50(1): 79-92. http://dx.doi.org/10.18273/revsal.v5 0n1-2018008

4. Ostrosky-Solis F. Características neuropsicológicas de la enfermedad de Parkinson. Rev. Neurol. 2000; 30, (80): 788-796

5. HornyKiewicz 0, Kirsh S. Neurochemical basis of dementia in Parkinson's disease. Can J Neurol Sci.1984; 11: 185-90

6. Méndez-Herrera C. El núcleo subtalámico en la fisiopatología de la enfermedad de Parkinson y su rol como diana quirúrgica. Rev. chil. neuro-psiquiatr. [Internet]. 2011 [citado 2018 Feb 25]; 49(1): 6268. http://dx.doi.org/10.4067/S071792272011000100008

7. Selby G. Stereotactic surgery for the relief of Parkinson's disease. Part I. A critical review. J Neurol Sci.1967; 5:315-42

8. Johnston $\mathrm{T}$, Rosvold H, Mishkin M. Projections from behaviorally defined sectors of the prefrontal cortex to the basal ganglia, septum and diencephalon of the monkeys. Exp Neurol. 1968; 21: 20-30

9. Ritz B. y Rhodes S. "After half a century of research on smoking and PD, where do we go now", Neurology. 2010; 74, (11): 870-871

10. Freed CR. Will embryonic stem cells be auseful source of dopamine neurons for transplant into patients with Parkinson's disease? Proc Natl Acad Sci USA 2002; 99:1755-1757

11. Lovell-Badge R. The future for stem cell research. Nature. 2001; 414:88-91

12. Temple $S$. The development of neural stem cells. Nature 2001; 414,112-117

13. Hernández P, Dorticós E. Medicina regenerativa: Células madre embrionarias y adultas. Rev Cubana Hematol Inmunol Hemoter [Internet]. 2004 [citado 2018 Feb 25]; 20(3). Disponible en: http://scielo.sld.cu/scielo.php?script= sci_arttext\&pid=S086402892004000300001\&lng=es

14. Verbally CM, Pera MF, Lansdorp PM. Stem cells: Hype and reality. Hematology 2002; 1:369-91

15. Cerón W, Lozada-Requena I, Ventocilla $\mathrm{K}$, Jara S, Pinto M, Cabello $\mathrm{M}$ et al. Células tronco mesenquimales: definiciones, cultivo y aplicaciones potenciales. Rev. Perú. Med. Exp. Salud pública [Internet]. 2016 [citado $2018 \mathrm{Feb} 25$ ]; $\quad 33(4)$ : 758-771.

http://dx.doi.org/10.17843/rpmesp.2 016.334 .2563

16. Prósper F, Gavira J, Herreros J, Rábago G, Luquin R, Moreno J et al. Trasplante celular y terapia regenerativa con SC. Anal Sist Sanit Navar 2006; 29:219-34

17. Pimentel-Parra G. Células madre, una nueva alternativa médica. Perinatología y Reproducción Humana.2017.31(1):28-33. doi.org/10.1016/j.rprh.2017.10.013

18. Politis M, Lindvall 0 . Clinical application of stem cell therapy in 
Parkinson's disease. BMC Med. 2012; 10: 1-7

19. Hernández $\mathrm{P}$, Medicina regenerativa y células madre. Mecanismos de acción de las células madre adultas. Revista Cubana de Hematología, Inmunología y Hemoterapia.2009; 25, (1)

20. Hernández P, Dorticos E. Medicina regenerativa Células madre embrionarias y adultas. Revista Cubana de Hematología, Inmunología y Hemoterapia. 2004; 20, (3)

21. Hughes A, Be-Sholomo Y, Daniel S, Lees A. What features improve the accuracy of clinical diagnosis in Parkinson's disease? Neurology. 1992; 42:11421146

22. Kim JH. Dopamine neurons derived from embryonic stem cells function in an animal model of Parkinson's disease. Nature. 2002; 418:50-16

23. Hernández $\mathrm{P}$, Medicina regenerativa y células madre. Mecanismo de acción de las células madre adultas. Scielo [En línea]. 2009 [Fecha de acceso 15 de junio del 2016]. Disponible en: http://scielo.sld.cu/scielo.php?script= sci_arttext\&pid=S086402892009000100002

24. Zapata L, García F. Preguntas y respuestas sobre medicina regenerativa. Scielo 2011; 10 (5): 1

25. Hernández P. Medicina Regenerativa II. Aplicaciones, realidad y perspectiva de la terapia celular. Scielo. 2006; 22; (1)

26. López M. Goya R. Medicina regenerativa para el tratamiento de enfermedades neurodegenerativas. ResearchGate [En línea]. 2015 [Fecha de acceso 16 de julio del 2016] Disponible en: https://rearchgate.net

27. Rodríguez J, Lu J, Velasco I, Rivera S, Zaghbi S, Liow S, et al. Persistent dopamine functions of neurons derived from embryonic stem cells in a rodent model of Parkinson disease. Stem Cells. 2007; 25: 918-928 